\title{
DAMPAK PEMANFAATAN BRIKET BATUBARA TERHADAP KUALITAS UDARA AMBIEN
}

\author{
${ }^{1}$ Rina Aprishanty, ${ }^{2}$ ssa Ansyori, ${ }^{2}$ Emalya Rahmawati, ${ }^{2}$ Puji Purwanti, , ${ }^{2}$ Ricky Nelson
}

(Diterima tanggal 15-11-2011; Disetujui tanggal 14-03-2012)

\begin{abstract}
ABSTRAK
Penggunaan Briket Batubara sebagai bahan bakar alternatif , perlu dikaji dampaknya terhadap kualitas udara.Pemantauan dilakukan di tempat penggunaan briket batu bara sebagai bahan bakar seperti industri kecil menengah , rumah makan dan pondok pesantren. Parameter yang diukur yaitu Debu, gas seperti $\mathrm{SO}_{2}, \mathrm{NO}_{2}, \mathrm{CO}$, dan Hidro karbon. Kualitas udara ambien di seluruh lokasi sampling berada di bawah baku mutu sesuai PP No. 41 tahun 1999.

Kata Kunci: Briket Batu Bara, Pencemar Udara
\end{abstract}

\begin{abstract}
The use of coal briquettes as an alternative fuel, is necessary to study their impact on the quality of air. Monitoring done in the use of coal briquettes as fuel such as small and medium industries, a restaurant and a boarding school. Parameters measured the Total Suspended Particulate, gases such as $\mathrm{SO}_{2}, \mathrm{NO}_{2}$, CO, and hydro carbon. Ambient air quality in all sampling locations under the quality standards appropriate. Ambient air quality in all sampling locations under the quality standards appropriate PP. 41 of 1999.
\end{abstract}

Keywords: Coal Briquette, Air Pollutants

\section{LATAR BELAKANG}

Pemerintah telah mencanangkan penggunaan briket batubara sebagai energi alternatif pengganti minyak tanah di industri kecilmenengah dan rumah tangga pada tahun 2005, sesuai dengan sasaran kebijakan energi nasional untuk tahun 2025. Namun demikian, dampak penggunaan briket batubara harus diwaspadai mengingat batubara mengandung komponen yang potensial untuk memberikan dampak terhadap manusia dan lingkungan setelah mengalami proses pembakaran. Oleh sebab diperlukan data-data yang komprehensif untuk mengantisipasi dampak penggunaan briket batubara ini terhadap lingkungan, sebagai dasar dalam pengambilan kebijakan pengendalian penggunaan briket batubara.
Pengkajian pemanfaatan briket batubara di masyarakat oleh PUSARPEDAL-KLH dimulai tahun 2006 hingga 2011. Pengkajian dilakukan melalui kegiatan pemantauan kualitas udara ambien untuk melihat dampak pemanfaatan briket batubara terhadap lingkungan hidup di beberapa daerah di Pulau Jawa. Pemantauan dilakukan melalui pengukuran parameter TSP, $\mathrm{SO}_{2}, \mathrm{NO}_{2}, \mathrm{CO}$, $\mathrm{HC}$ sesuai parameter baku mutu yang terdapat dalam Lampiran Peraturan Pemerintah No. 41 tahun 1999 tentang Pengendalian Pencemaran Udara. Daerah yang dipilih adalah daerah yang terdapat kegiatan pemanfaatan briket batubara sebagai bahan bakar, seperti: industri kecil menengah, rumah makan dan pondok pesantren.

\footnotetext{
1) Widyaiswara Pusat Pendidikan dan Pelatihan Lingkungan Hidup -Deputi VII KLH, Kawasan Puspiptek Gedung 210, Serpong, Banten, 15310-Indonesia.

${ }^{2}$ Pusat Sarana Pegendalian Lingkungan Hidup -Deputi VII KLH, Kawasan Puspiptek Gedung 210, Serpong, Banten, 15310-Indonesia
} 


\section{TUJUAN}

Mengetahui kualitas udara di sekitar daerah pemanfaatan briket batu bara dan kontrol Lokasi kontrol adalah lokasi tanpa pengaruh dari kegiatan pemanfaatan briket batubara dan masih dalam daerah yang sama dengan lokasi kegiatan.

\section{METODE}

Metode dilakukan dengan metode eksperimen untuk mendapatkan data primer.Data diperoleh dengan pengukuran langsung di lokasi

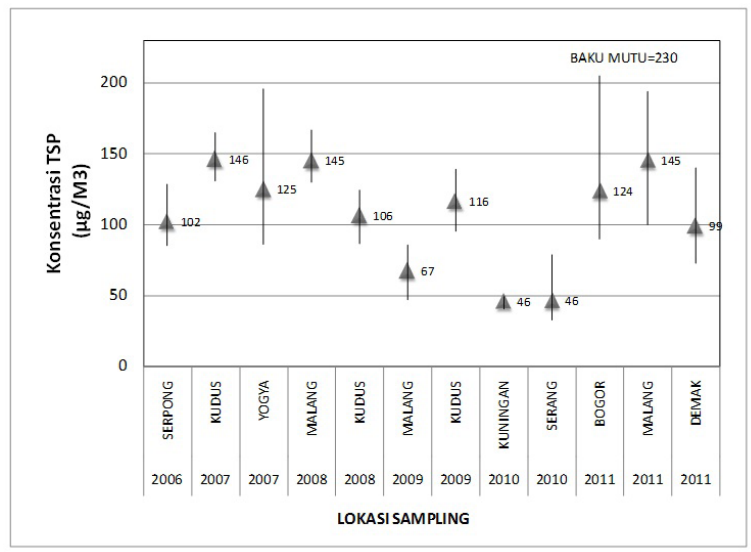

Gambar 1A. Sebaran konsentrasi parameter TSP di udara ambien di beberapa lokasi kegiatan

Gambar 1A dan 1B di atas menunjukkan bahwa hasil seluruh pengukuran untuk parameter Total Suspended Particulate (TSP) yang dilakukan di berbagai daerah mulai dari pembakaran briket batu bara melalui analisis dan perlakuan contoh uji dengan menggunakan metode dan peralatan standar sesuai parameter polutan udara yang diuji.

\section{HASIL DAN PEMBAHASAN}

Berikut adalah hasil pengukuran yang ditampilkan dalam bentuk grafik hasil perhitungan rata-rata, minimum dan maksimum dari beberapa lokasi pengukuran di suatu daerah pada masing-masing periode pengukuran:

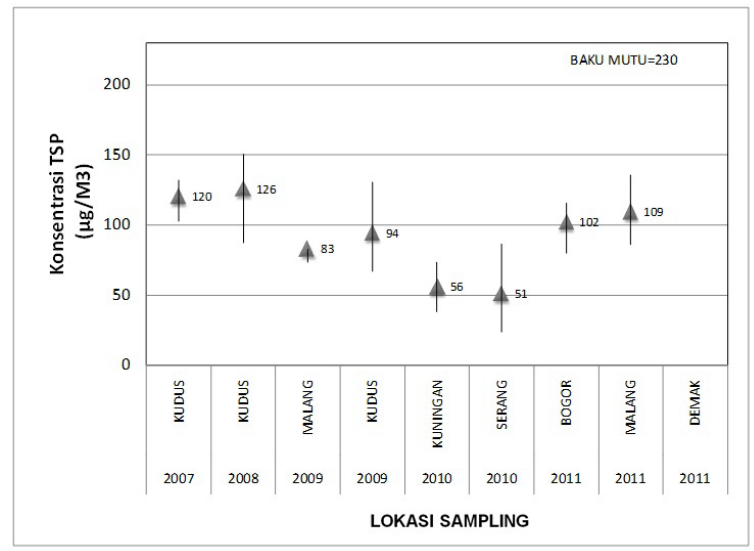

Gambar 1B. Sebaran konsentrasi parameter TSP di udara ambien di beberapa lokasi kontrol

tahun 2006 sampai dengan 2011 masih di bawah Baku Mutu kualitas udara ambien; dengan konsentrasi TSP relatif sama antara lokasi kegiatan dan lokasi kontrol. 


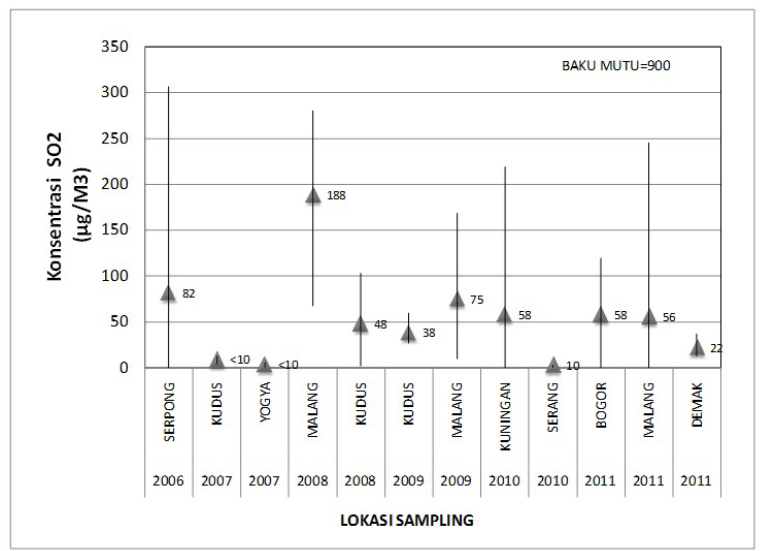

Gambar 2A. Sebaran konsentrasi parameter SO2 di udara ambien di beberapa lokasi kegiatan

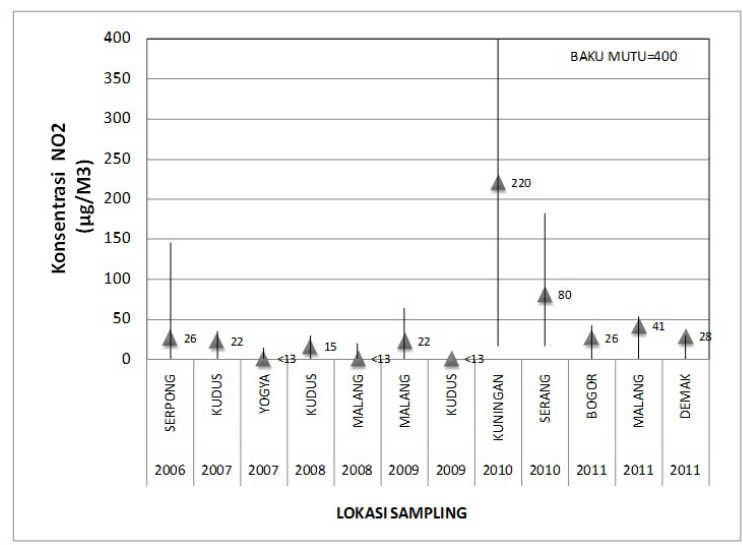

Gambar 3A. Sebaran konsentrasi parameter NO2 di udara ambien di beberapa lokasi kegiatan

Gambar2A, 2B, 3Adan 3B di atas menunjukkan bahwa hasil seluruh pengukuran untuk parameter sulfur dioksida $\left(\mathrm{SO}_{2}\right)$ dan nitrogen dioksida $\left(\mathrm{NO}_{2}\right)$ yang dilakukan di berbagai

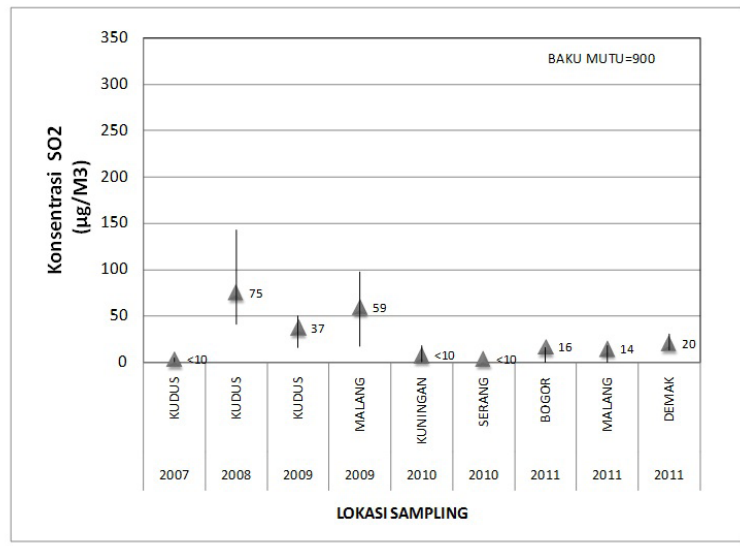

Gambar 2B. Sebaran konsentrasi parameter SO2 di udara ambien di beberapa lokasi kontrol

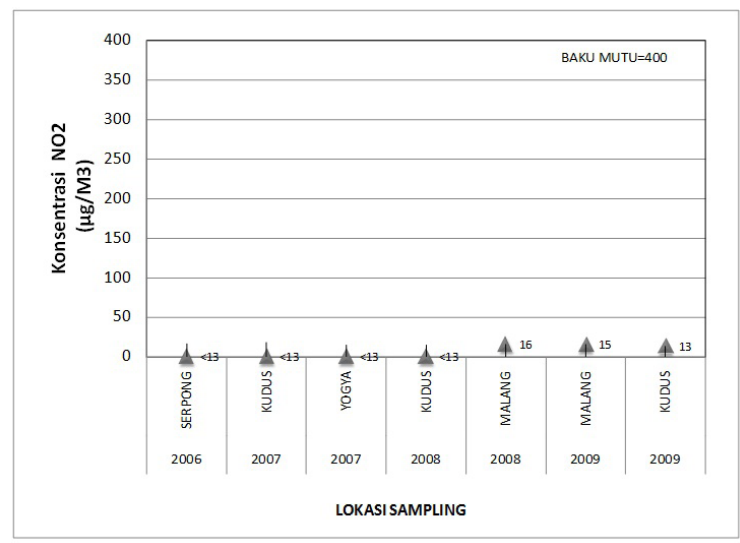

Gambar 3B. Sebaran konsentrasi parameter NO2 di udara ambien di beberapa lokasi kontrol

daerah mulai dari tahun 2006 sampai dengan 2011 masih di bawah baku mutu kualitas udara ambien; dengan konsentrasi relatif lebih kecil untuk lokasi kontrol. 


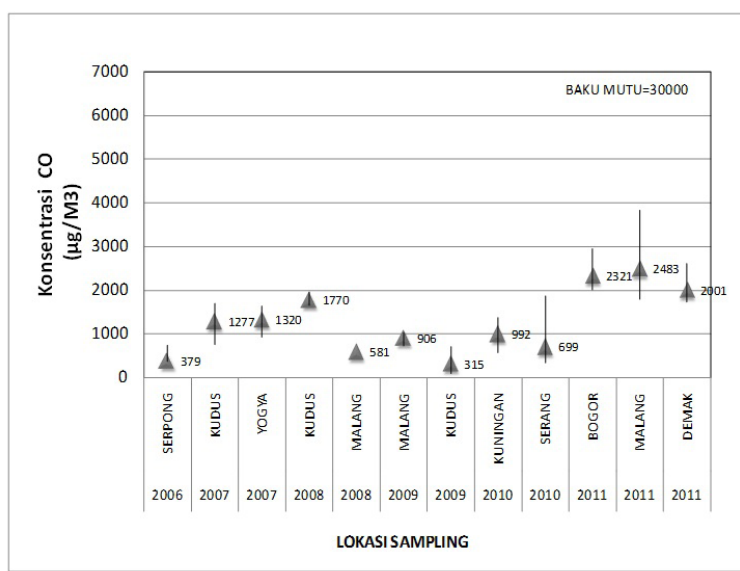

Gambar 4A. Sebaran konsentrasi parameter CO di udara ambien di beberapa lokasi kegiatan

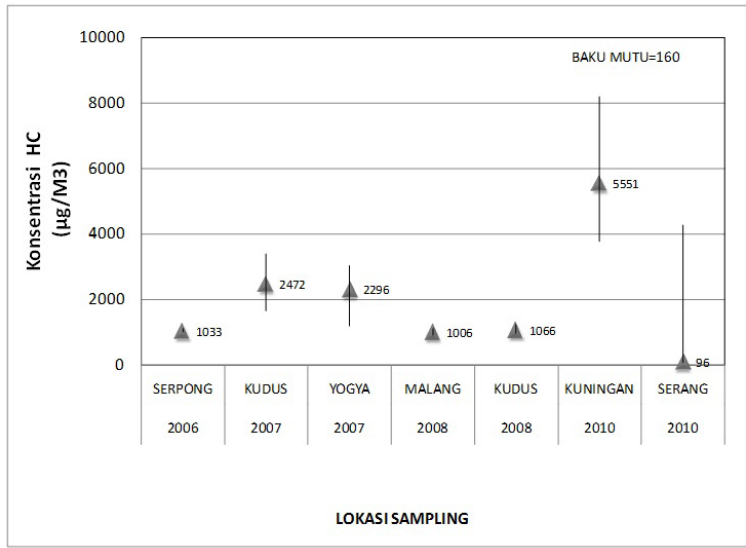

Gambar 5A. Sebaran konsentrasi parameter HC di udara ambien di beberapa lokasi kegiatan

Gambar 4 di atas menunjukkan bahwa hasil seluruh pengukuran untuk parameter karbon monoksida (CO) yang dilakukan di berbagai daerah mulai dari tahun 2006 sampai dengan 2011 masih di bawah baku mutu kualitas udara ambien; dengan konsentrasi CO relatif sama antara lokasi kegiatan dengan lokasi kontrol. Gambar 5 di atas menunjukkan bahwa hasil seluruh pengukuran untuk parameter hidrokarbon (HC) yang dilakukan di berbagai daerah mulai dari tahun 2006 sampai dengan 2011 melebihi Baku Mutu kualitas udara ambien; baik untuk lokasi kegiatan

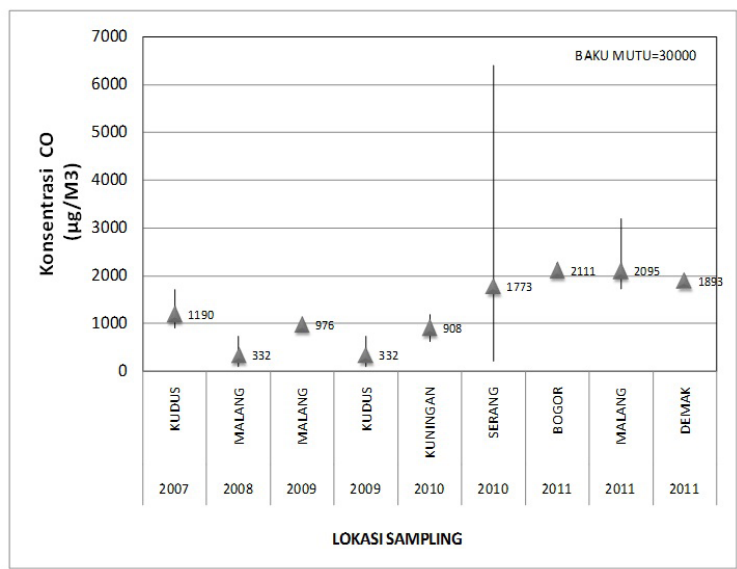

Gambar 4B. Sebaran konsentrasi parameter CO di udara ambien di beberapa lokasi kontrol

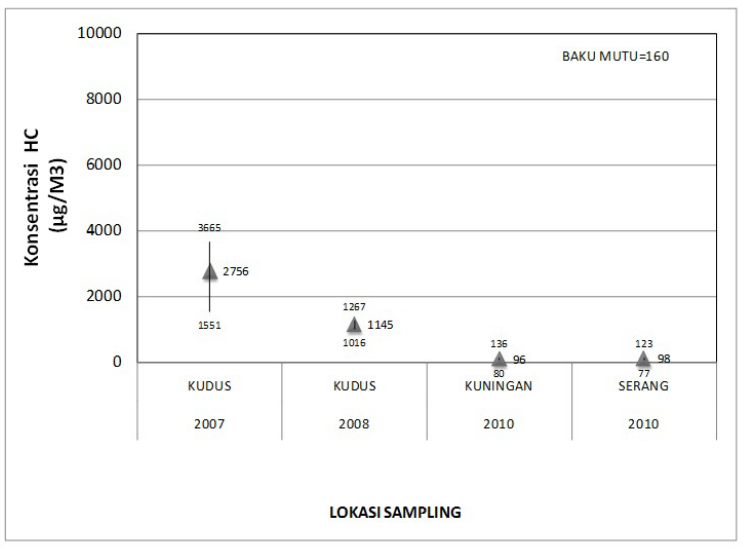

Gambar 5B. Sebaran konsentrasi parameter HC di udara ambien di beberapa lokasi kontrol

maupun lokasi kontrol. Sebagai catatan, kondisi konsentrasi melebihi baku mutu untuk parameter $\mathrm{HC}$ di udara ambien selalu terjadi di berbagai pengukuran; hal ini perlu menjadi perhatian dikarenakan baku mutu yang ditetapkan di peraturan saat ini tidak mencantumkan ketentuan apakah hidrokarbon yang diukur adalah sebagai total atau sebagai hidrokarbon non metana. Konsentrasi latar untuk hidrokarbon metana di Indonesia yang cukup tinggi merupakan kontribusi terbesar nilai baku mutu terlampaui. 


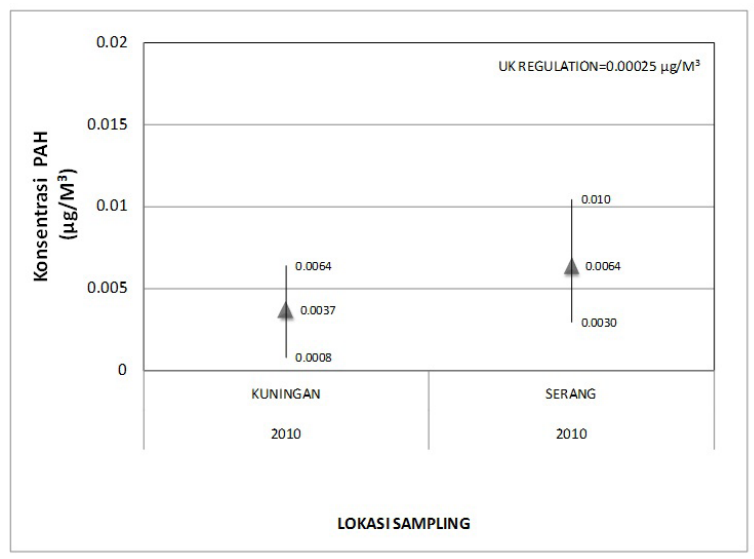

Gambar 6A. Sebaran konsentrasi parameter PAH di udara ambien di beberapa lokasi kegiatan

Gambar 6 di atas menunjukkan bahwa konsentrasi parameter PAH terdeteksi sebesar $0,0037 \mu \mathrm{g} / \mathrm{M}^{3}$ dan $0,0064 \mu \mathrm{g} / \mathrm{M}^{3}$ di masingmasing lokasi pengukuran di daerah Kuningan dan Serang; sebagai pembanding, pemerintah Inggris pada tahun 2001 menetapkan target baku mutu ambien PAH sebesar $0,00025 \mu \mathrm{g} /$ $\mathrm{M}^{3}$. Adapun konsentrasi PAH terdeteksi tidak signifikan untuk lokasi kontrol.

Konsentrasi selama periode 2006 - 2011 pada semua parameter cenderung rendah, hal ini disebabkan karena pada periode tersebut terjadi kemarau basah, sehingga polutan tercuci oleh air hujan.

\section{KESIMPULAN}

Hasil pengukuran parameter kualitas udara ambien menunjukkan kualitas udara ambien di seluruh lokasi sampling berada di bawah baku mutu sesuai PP No. 41 tahun 1999, kecuali untuk parameter hidrokarbon (HC) hasil pengukuran di atas nilai baku mutu $160 \mu \mathrm{g} /$ $\mathrm{M}^{3}$. Adapun konsentrasi PAH di udara ambien pada lokasi kegiatan terdeteksi melebihi nilai di negara Inggris $0,00025 \mu \mathrm{g} / \mathrm{M}^{3}$;

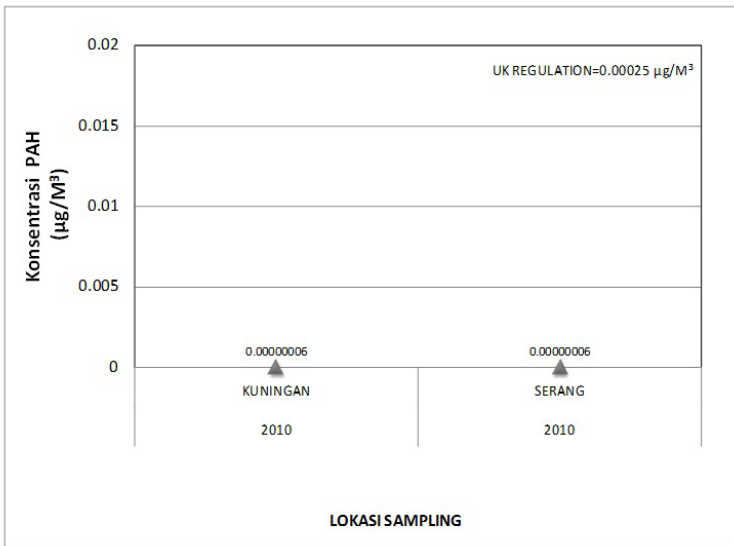

Gambar 6B. Sebaran konsentrasi parameter PAH di udara ambien di beberapa lokasi kontrol

\section{DAFTAR PUSTAKA}

(1) Aprishanthy Rina, 2011, Laporan Pengkajian Briket Batu Bara 2006 -2011. Pusarpedal -Deputi VII. Kementrian Lingkungan Hidup . Serpong

(2) Farhani Novy, et al, 2010, Status Deposisi Asam Di Indonesia Tahun 2001 - 2008. Pusarpedal -Deputi VII.Kementrian Lingkungan Hidup Serpong

(3) Gindo S Agus.2010.Kondisi Cuaca Kawasan Nuklir Serpong, Prosiding Seminar Nasional Teknologi Pengelolaan Limbah VIII Pusat Teknologi Limbah RadioaktifBATAN .Serpong.ISSN 1410-6086

(4) Nasrullah, 2011. Perubahan Iklim dan Trend data Iklim, http://www.bmkg. go.id. Didownload 18 September 2012 .

(5) Peraturan Pemerintah No. 41 Tahun 1999 Tentang : Pengendalian Pencemaran Udara. Kemetrian Lingkungan Hidup Republik Indonesia. Jakarta

(6) Rita, 2007. Studi Kualitas Udara di Sekitar Briket Batu Bara, Pasca Sarjana Universitas Indonesia. Tesis. Jakarta 
(7) Riyadi Novrian, 2011, Penggunaan Briket Batubara sebagai Sumber Energi Alternatif. http://teknologi. kompasiana.com/terapan/2011/10/05/ penggunaan-briket-batubara-sebagaisumber-energi-alternatif/ Didownload 11 Oktober 2011.

(8) Widarti Enik Sri; Sarwono, dan Hantoro,Ridho, Studi Eksperimental Karakeristik Briket Organik Dengan
Bahan Baku Dari PPLH Seloliman. Jurusan Teknik Fisika FTI ITS Surabaya. Kampus ITS Keputih Sukolilo, Surabaya

(9) Kepmen ESDM NO.47 Tahun 2006 Tentang Pedoman Pembuatan dan Pemanfaatan Briket Batubara dan Bahan Bakar Padat Berbasis Batubara. 